\title{
UJI PRAKLINIS EFEK HIPOGLIKEMIK BLIMBING WULUH (AVERRHOA BILIMBI L.) DAN DAUN TAPAK DARA(CATHARANTHUS ROSEUS G)
}

\section{PRECLINICAL STUDY OF HYPOGLYCEMIC EFFECT OF BLIMBING WULUH (AVERRHOA BILIMBI L.) AND LEAVES OF TAPAK DARA (CATHARANTHUS ROSEUS G)}

\author{
EM Sutrisna*1, Sahila Ermawati ${ }^{2}$, Mulyadin ${ }^{2}$, Mios Agung $\mathbf{S P}^{2}$ \\ ${ }^{1}$ Fakultas Farmasi, Universitas Muhammadiyah Surakarta \\ ${ }^{2}$ Fakultas Kedokteran, Universitas Muhammadiyah Surakarta \\ em_sutrisna@yahoo.com
}

\begin{abstract}
ABSTRAK
Beberapa penelitian sebelumnya menyatakan bahwa perasan air blimbing wuluh (Averrhoa bilimbi L.)dan dekokta daun tapak dara (Catharanthus roseus G) mampu menurunkan kadar glukosa darah pada hewan uji. Penelitian ini bertujuan menguji efek hipoglikemik dari buah blimbing wuluh (Averrhoa bilimbi L.) dan daun tapak dara (Catharanthus roseus $G$ ) dengan larutan penyari etanol $70 \%$. Sebanyak 40 ekor tikus putih jantan (Rattus norvegicus) galus Wistar dibagi dalam 8 kelompok dan diukur kadar glukosa darah puasanya (GD1). Semua tikus kemudian diinjeksi alloksan monohydrate dosis 30mg/200g bb tikus secara intraperitoneal dan diukur kadar glukosa darah puasanya (GD2). Setelah itu, tikus pada Kelompok I diberi aquadest ad libitum selama 7 hari, kelompok II diberi glibenklamid 0,126 mg/200g BB $1 x$ pemberian. Kelompok III sampai V diberi ekstrak etanol $70 \%$ blimbing wuluh berturut-turut dosis 20mg/200g tikus, $40 \mathrm{mg} / 200 \mathrm{~g}$ tikus, $80 \mathrm{mg} / 200 \mathrm{~g}$ tikus. Kelompok VI-VIII diberi ekstrak etanol $70 \%$ daun tapak dara berturutturut dosis 20mg/200g tikus, 40mg/200g tikus, 80mg/200g tikus. Semua ekstrak diberikan per oral selama 7 hari. Semua tikus kemudian diukur kadar glukosa darah puasanya (GD3). Hasil penelitian menunjukkan bahwa ekstrak etanol 70\% blimbing wuluh dosis 20g/200g; 40g/200g dan 80g/200g mampu menurunkan kadar glukosa darah dengan persen penurunan berturut-turut sebesar 42,51\%; 43,40\% dan 58,95\%. Ekstrak etanol 70\% daun tapak dara(Catharanthus roseus G) dosis 20g/200g; 40g/200g dan 80g/200g mampu menurunkan kadar glukosa darah dengan persen penurunan berturut-turut sebesar 43,46\%; 53,70\% dan $58,85 \%$
\end{abstract}

Kata kunci: Hipoglikemik, Averrhoa bilimbi L. dan Catharanthus roseus G

ABSTRACT

Previous studies showed that Blimbing wuluh (Averrhoa bilimbi L.) and decocta of leaves of Tapak dara(Catharanthus roseus $G$ ) can lower blood glucose levels in test animals. This experiment was aimed to examine the hypoglycemic effect of $70 \%$ ethanol extract of fruit Blimbing wuluh (Averrhoa bilimbi L.) and leaf of Tapak dara (Catharanthus roseus G).Male white rats (Rattus norvegicus) Wistar strain (40) were divided into eight group. Each group consist of 5 rats. All rats were measured fasting blood glucose level (GD1). After that, all rats were injected by alloxan monohydrate 30mg/200g bw and then were measured fasting blood glucose level (GD2) on third day. Group I were treated by water for injection (WFI) ad libitum. Group II were treated by glibenclamide $0.126 \mathrm{mg} / 200 \mathrm{~g}$ bw once a day. Group III to V were treated by $70 \%$ ethanol extract of Blimbing wuluh 20mg/200g bw; 40mg/200g bw and 80mg/200 $\mathrm{gw}$ respectively. Group VIVIII were treated by $70 \%$ ethanol extract of leaves of Tapak dara 20mg/200g $\mathrm{gw}$; 40mg/200gbw, $80 \mathrm{mg} / 200 \mathrm{gbw}$ respectively. All the extracts were treated orally for 7 days. Then all rats were measured in fasting blood glucose levels (GD3). The results showed that the 70\% ethanol extract of Blimbing wuluh (Averrhoa bilimbi L.) 20mg/200g bw; $40 \mathrm{mg} / 200 \mathrm{~g} \mathrm{bw}$ and $80 \mathrm{mg} / 200 \mathrm{~g} \mathrm{bw}$ able to reduce blood glucose levels with the percentage of reduction 42,51\%; 43,40\% and 58,95\% respectively. The $70 \%$ ethanol extract of leaves of Tapak dara (Catharanthus roseus G) 20mg/200g bw; 40mg/200g bw and 80mg/200g bw able to reduce blood glucose levels with the percentage of reduction 43,46\%; 53,70\% and 58,85\% respectively

Key words: hypoglycemic, Blimbing wuluh (Averrhoa bilimbi L.) and leaves tapak dara (Catharanthus roseus $G$ )

\section{PENDAHULUAN}

Eksplorasi tanaman asli Indonesia sebagai agen fitofarmaka terus digalakkan. Lebih dari 400 tanaman dilaporkan digunakan secara empiris untuk mengobati diabetes (Subroto, 2006). Dua macam tanaman yang saat ini banyak diteliti untuk menurunkan kadar gula darah adalah blimbing wuluh dan tapak dara.
Blimbing wuluh banyak digunakan dalam mengobati berbagai keluhan. Antara lain antibakteri, antiskorbut, astringent, mengobati demam, mumps, diabetes, sipilis, batuk, hipertensi, ulkus lambung (Kumar, et al., 2011).Vitamin dan mineral yang terdapat dalam buah belimbing antara lain ribovlavin, vitamin $\mathrm{B} 1$, niacin, asam askorbat, carotene, vit A, sedang mineralnya antara lain 
phosphor, kalsium dan besi (Anita et al, 2011). Ekstrak etanol daun Blimbing wuluh mampu menurunkan kadar glukosa darah sebesar 50\%, menurunkan kadar trigliserida $130 \%$, dan menaikkan HDL sebesar 60\% (Pushparaj, et al., 2000). Pada uji toksisitas dinyatakan bahwa pemberian jus blimbing wuluh selama 15 hari dosis $1 \mathrm{~g} / \mathrm{kgbb}$ tidak menyebabkan toksik pada mencit (Ambili, et al., 2009).

Dekokta daun dan tanaman utuh (whole plant ) tapak dara (Catarathus roseus), telah digunakan sebagai obat diabetes dibeberapa Negara antara lain Brazil, dominica, Enggris, Jamaica, mosmabiq, Pakistan, Taiwan, Tailan (Don, 1999). Jus daun segar Catharantus roseus dilaporkan dapat menurunkan kadar glukosa darah pada kelinci yang diinduksi alloksan (Nammi, et al., 2003). Campuran ekstrak methanol dan dikloromethane, perbandingan (1:1) mempunyai efek hipoglikemik pada tikus yang diinduksi streptozosin (Sing et al., 2001). Ekstrak air daun Cataranthus roseus yang diberikan selama 15 hari dosis tunggal $500 \mathrm{mg} / \mathrm{kgbb}$ mampu menurunkan kadar glukosa darah (290.33-156.33 mg/dL) pada tikus albino yang diinduksi streptozotocin (Prasad, 2009).Penelitian Armenia dan kawan-kawan tahun 2004, membuktikan bahwa air perasan blimbing wuluh dosis $30 \mathrm{ml} / \mathrm{kgBB}$ mencit, mampu menurunkan kadar glukosa darah dengan persen penurunan sebesar $55,27 \%$ pada mencit yang diinduksi dengan aloksan. Penelitian lain menyataka bahwa dekokta daun tapak dara mampu menurunkan kadar gula darah pada tikus yang diinduksi aloksan dengan persen penurunan 20\% (Anggarani, 2005).

Penelitian ini melanjutkan penelitian di atas dengan menguji efek penurunan kadar glukosa darah buah blimbing wuluh dan daun tapak dara dengan cairan penyari etanol $70 \%$.

\section{METODE PENELITIAN}

\section{Alat dan Bahan}

Alat : spuit needle feeding, tabung mikrokapiler, ependorft, sentrifuge, Star Dust FC15.

Bahan : buah blimbing wuluh, daun tapak dara, GOD PAP reagen, alloksan monohydrate, etanol $70 \%$, aquadest

Hewan uji: tikus putih jantan (Rattus norvegicus) galus Wistar

\section{Jalannya Penelitian}

1. Determinasi tanaman uji dilakukan di FKIP laboratorium Biologi Universitas Muhammadiyah Surakarta

2. Ekstraksi tanaman uji dilakukan dengan maserasi dengan cairan penyari etanol $70 \%$. Cara ekstraksi sebagai berikut: simplisia kering dari blimbing wuluh dan tapak dara direndam dalam etanol $70 \%$ dengan perbandingan 1;7,5 dengan sesekali diaduk. Setelah 2 hari filtrat dipisahkan dari residu. Residu direndam lagi dengan etanol $75 \%$ perbandingan 1:4 selama 2 hari. Setelah dua hari filtrat dituang dan digabungkan dengan filtrat yang pertama. Gabungan filtrat tersebut diuapkan dengan vacuum evaporator sampai didapatkan esktrak kental.

3. Pengujian kadar gula darah

a. Hewan uji dikelompokan dalam 8 kelompok. Masing-masing kelompok berjumlah 5 tikus. Diadaptasikan selama 1 minggu

b. Setelah 1 minggu semua tikus diperiksa kadar glukosa darah puasanya (GD1)

c. Kemudian semua tikus uji diinduksi dengan alloksan monohydrate dosis $30 \mathrm{mg} / 200 \mathrm{~g}$ bb tikus secara intraperitoneal

d. Tikus kemudian dipuasakan selama 16 jam, kemudian diukur kadar glukosa darah (GD2)

e. Setelah itu, tikus pada Kelompok I diberi aquadest ad libitum selama 7 hari, kelompok II diberi glibenklamid 0,126 $\mathrm{mg} / 200 \mathrm{~g}$ bb 1x pemberian. Kelompok III sampai V diberi ekstrak etanol $70 \%$ blimbing wuluh berturut-turut dosis $20 \mathrm{mg} / 200 \mathrm{~g}$ tikus, $40 \mathrm{mg} / 200 \mathrm{~g}$ tikus, $80 \mathrm{mg} / 200 \mathrm{~g}$ tikus. Kelompok VI-VIII diberi ekstrak etanol $70 \%$ daun tapak dara berturut-turut dosis $20 \mathrm{mg} / 200 \mathrm{~g}$ tikus, $40 \mathrm{mg} / 200 \mathrm{~g}$ tikus, $80 \mathrm{mg} / 200 \mathrm{~g}$ tikus. semua ekstrak diberikan per oral selama 7 hari.

f. Pada hari ke-8 semua tikus diukur kadar glukosa darah puasanya(GD3)

\section{HASIL DAN PEMBAHASAN}

Hasil ekstraksi dengan etanol $70 \%$ terhadap simplisa blimbing wuluh sebesar $12,2 \%$ dan tapak dara sebesar $16,5 \%$. Kedua ekstrak diuji kadar glukosa darahnya.Rerata kadar glukosa darah dapat dilihat pada Tabel 1

Tabel 1- Rerata kadar glukosa darah awal, post alloksan dan kadar glukosa akhir

\begin{tabular}{llll}
\hline Kelompok & Awal (mg/dL) & $\begin{array}{l}\text { Post Aloksan } \\
(\mathrm{mg} / \mathrm{dL})\end{array}$ & Akhir (mg/dL) \\
\hline Kontrol (-) akuadest & $98.20 \pm 14.22$ & $269.20 \pm 75.76$ & $380.60 \pm 221.13$ \\
Kontrol (+) glibenklamid & $91.60 \pm 10.52$ & $248.60 \pm 66.99$ & $145.60 \pm 38.96^{*}$ \\
Ekstrak etanol 70\% blimbing wuluh $20 \mathrm{~g} / 200 \mathrm{~g} \mathrm{bb}$ & $96.60 \pm 15.62$ & $311.40 \pm 36.4$ & $218.80 \pm 84.95^{*}$ \\
Ekstrak etanol 70\% blimbing wuluh 40g/200g bb & $82.40 \pm 10.11$ & $292 \pm 30.5$ & $215.40 \pm 65.75^{*}$ \\
Ekstrak etanol 70\% blimbing wuluh $80 \mathrm{~g} / 200 \mathrm{~g} \mathrm{bb}$ & $93.8 \pm 22.72$ & $285.20 \pm 65.73$ & $156.20 \pm 24.95^{*}$ \\
Ekstrak etanol 70\% daun tapak dara $20 \mathrm{~g} / 200 \mathrm{~g} \mathrm{bb}$ & $94.00 \pm 15.73$ & $254.40 \pm 18.51$ & $214.80 \pm 32.44 *$ \\
Ekstrak etanol 70\% daun tapak dara 40g/200g bb & $90.40 \pm 12.68$ & $275.20 \pm 35.4$ & $176.20 \pm 73.60^{*}$ \\
\hline
\end{tabular}




\begin{tabular}{llll}
\hline Ekstrak etanol $70 \%$ daun tapak dara $80 \mathrm{~g} / 200 \mathrm{~g} \mathrm{bb}$ & $87.20 \pm 12.27$ & $248.80 \pm 86.71$ & $156.60 \pm 26.29 *$ \\
\hline Keterangan: *: berbeda signifikan dengan control negatif & &
\end{tabular}

Data kadar glukosa darah awal, glukosa post induksi alloksan dan glukosa akhir dianalisis distribusinya dengan Sapiro Wilk dan homogenitas data dengan Test of Homogenecity of Variance. Hasil uji Sapiro Wilk didapatkan nilai p 0,642 $(\mathrm{P}>0,05)$. Hal ini berarti data terdistribusi normal. Pada Test of Homogenecity of Variance dengan levene test didapatkan nilai $\mathrm{P} 0,327(\mathrm{P}>0,05)$. Hal ini berarti data homogen. Karena data terdistribusi normal dan homogen maka kadar glukosa awal diuji dengan annova. Hasilnya adalah P. 0,217. Hal ini berarti kadar glukosa awal tidak berbebda signifikan.

Pada uji Sapiro Wilk kadar glukosa post induksi alloksan didapatkan nilai p 0,318 $(\mathrm{P}>0,05)$. Hal ini berarti data terdistribusi normal. Pada Test of Homogenecity of Variance dengan levene test didapatkan nilai P 0,427 ( $>>0,05)$. Hal ini berarti data homogen. Karena data terdistribusi normal dan homogen maka kadar glukosa awal diuji dengan annova. Hasilnya adalah P. 0,325. Hal ini berarti kadar glukosa awal tidak berbeda signifikan. Karena kadar glukosa post alloksan tidak berbeda signifikan, maka penentuan perbedaan efek penurunan glukosa dilhiat dari kadar glukosa akhir saja.

Pada kadar glukosa akhir, uji Shapiro Wilk didapatkan data $\mathrm{p}$ 0,463 ( $\mathrm{P}>0,05)$, sedang pada uji Levene didapatkan nilai P.0, $528(\mathrm{P}>0,05)$. Hal ini berarti data terdistribusi normal dan homogen. Pada uji anova didapatkan nilai P. 0,003 $(\mathrm{P}<0,05)$. Hal ini berarti terdapat perbedaan bermakna kadar glukosa darah antar kedelapan kelompok perlakuan tersebut. Pada uji LSD didapatkan hasil bahwa ekstrak ethanol $70 \%$ blimbing wuluh dan tapak dara berbebeda signifikan dengan kontrol negatif (tabel 1)

Pada perhitungan persen penurunan kadar glukosa darah menunjukkan bahawa semakin tinggi dosis ekstrak etanol $70 \%$ blimbing wuluh maupun daun tapak dara semakin besar penurunan kadar glukosa darah (tabel 2).
Tabel 2- Persen penurunan kadar glukosa darah

\begin{tabular}{ll}
\hline Glibenklamid $0,126 \mathrm{mg} / 200 \mathrm{~g}$ tikus & $\%$ penurunan \\
Ekstrak etanol $70 \%$ blimbing wuluh & 61.74 \\
$20 \mathrm{~g} / 200 \mathrm{~g}$ tikus & 42.51 \\
$\begin{array}{l}\text { Ekstrak etanol } 70 \% \text { blimbing wuluh } \\
\text { 40g/200g tikus }\end{array}$ & 43.40 \\
$\begin{array}{l}\text { Ekstrak etanol } 70 \% \text { blimbing wuluh } \\
80 \mathrm{~g} / 200 \mathrm{~g} \text { tikus }\end{array}$ & 58.95 \\
$\begin{array}{l}\text { Ekstrak etanol } 70 \% \text { daun tapak dara } \\
20 \mathrm{~g} / 200 \mathrm{~g} \text { tikus }\end{array}$ & 43.56 \\
$\begin{array}{l}\text { Ekstrak etanol } 70 \% \text { daun tapak dara } \\
40 \mathrm{~g} / 200 \mathrm{~g} \text { tikus }\end{array}$ & 53.70 \\
$\begin{array}{l}\text { Ekstrak etanol } 70 \% \text { daun tapak dara } \\
80 \mathrm{~g} / 200 \mathrm{~g} \text { tikus }\end{array}$ & 58.85 \\
\hline
\end{tabular}

Pada penelitian ini terbukti bahwa ekstrak etanol $70 \%$ belimbing wuluh (Averrhoa bilimbi L) mampu menurunkan kadar glukosa darah tikus yang diinduksi alloksan. Hal ini mendasari pemikiran bahwa senyawa-senyawa yang diduga berefek sebagai agen hipoglikemik adalah senyawa semi polar. Senyawa flavonoid yang terdapat dalam blimbing wuluh (Averrhoa bilimbi L) diduga mempunyai kemampuan meregenerasi dan merangsang pelepasan insulin oleh sel beta pancreas (Dheer dan Bhatnagar, 2010).

Esktra etanol $70 \%$ daun tapak dara (Catarathus roseus G. Don) pada penelitian ini juga terbukti memiliki kemampuan mampu menurunkan kadar glukosa darah. Dengan melihat penelitian lain yang membuktikan bahwa dekokta, jus dan ekstrak methanol daun tapak dara juga mampu menurunkan kadar glukosa darah, maka diduga senyawa-senyawa yang berefek hipoglikemik tersebut adalah senyawa yang sifatnya polar dan semi polar. Salah satu senyawa dalam kandungan tapak dara (Catarathus roseus G. Don) yang diduga mempunyai kemampuan menurunkan kadar glukosa darah adalah flavonoid terutama quersetin. Flavonoid secara umum diduga memiliki kemampuan meregenerasi dan merangsang pelepasan insulin pada sel beta pancreas (Dheer dan Bhatnagar, 2010). Sedang quersetin diduga mampu menghambat transport glukosa oleh GLUT2 dan GLUT5 (Piparo, et al., 2008 dan Patel, 2009).

Penelitian ini menunjukkan bahwa ekstrak etanol $70 \%$ belimbing wuluh (Averrhoa bilimbi L) dan ekstrak etanol 70\% daun tapak dara (Catarathus roseus G. Don) memiliki kemampuan yang sama dalam menurunka kadar glukosa darah pada tikus yang diinduksi alloksan.

\section{KESIMPULAN}

1. Ekstrak etanol $70 \%$ belimbing wuluh (Averrhoa bilimbi L) mampu menurunkan kadar glukosa darah tikus putih jantan (Rattus norvegicus) galus Wistar yang diinduksi alloksan

2. Ekstrak etanol $70 \%$ daun tapak dara (Catarathus roseus G. Don) mampu 
menurunkan kadar glukosa darah tikus putih jantan (Rattus norvegicus) galur Wistar yang diinduksi alloksan

3. Kemampuan menurunkan kadar glukosa darah dari ekstrak etanol $70 \%$ belimbing wuluh
(Averrhoa bilimbi L) dan ekstra etanol $70 \%$ daun tapak dara (Catarathus roseus G. Don) adalah sama.

\section{DAFTAR PUSTAKA}

Ambili,S.,Subramoniam,A., Nagarajan,N.S., 2009, Studies on the Antihyperlipidemic Properties of Averrhoa bilimbi Fruit in Rats, Planta Med; 75(1) : 55-58

Anggraini, N. 2005. Pengaruh dekok daun tapak dara (catharanthus roseus) sebagai anti hiperglikemia pada tikus (rattus norvegikus) yang diinduksi aloksan. Malang : FKIP UMM

Anita, R.Y., Geetha, R.V., \& Laksmi, T., 2011, Averrhoa bilimbi Linn-Nature's Drug Store- A Pharmacological Review, Inter. J. of Drug Development \& Research, Vol. 3, Issue 3 ,101-108.

Armenia, Megawati, dan Rusdi., 2004. Efek Penurunan Gula Darah Air Perasan Buah Belimbing Wuluh Pada Mencit Diabetes Yang Diinduksi Aloksan Dan Mencit Yang Dibebani Glukosa. Jurnal sains dan teknologi farmasi. Vol 9:62-9

Don, G., 1999. Catharanthus roseus In: Ross I.A. (Ed.), Medicinal plants of the world. Human Press, Totowa, NJ, pp. 109-118

Dheer R. dan Bhatnagar P., 2010. A study of the Antidiabetic Activity of Barleria prionitis Linn. Indian Journal of Pharmacology. Vol 42 (2): 70-3.

Tjitrosoepomo,G., 1998. Taksonomi Tumbuhan Spermatophyta. Yogyakarta: UGM Press

Kumar, A.S., Kavimani,S., \& Jayaveera, K.N., 2011, review on medicinal plants with potential antidiabetic activity, Int. J. of Phytopharmacology, 2(2), 53-60.

Nammi. S.. Boini. M.K..Lodagala. S.D.. and Behara. R.B.. 2003.The iuice of fresh leaves ofCatharanthus roseus Linn. reduces blood glucose in normal and alloxan diabetic rabbits, BMC Complementary and Alternative Medicine, vol. 3, article 4

Petel J. A Review of Potensial Health Benefits of Flavonoids. LURJ (Serial oneline) 2008 (cited 2009 may 22);3:2. Available from: http//www.lurj.org

Piparo E.,2008, Flavonoids for Controlling Starch Disgestion: Structural Reguirements for Inhibiting Human a-Amylase. J Med Chem. Vol. 51, No. 12.

Prasad. S.K.. Kulshreshtha. A.. and Oureshi.T.N.. 2009. Antidiabetic activitv of some herbal plants in streptozotocin induced diabetic albino rats, Pakistan Journal of Nutrition, vol. 8, no. 5, pp. 551-557

Pushparaj, P., Tan C.H., dan Tan BK., 2000, Effects of Averrhoa bilimbi leaf extract on blood glucose and lipids in streptozotocin-diabetic rats, J Ethnopharmacol. 72(1-2):69-76.

Singh. S.N.. Vats.P.. and Suri. S..2001. Effect of an antidiabetic extract of Catharanthus roseus on enzvmic activities in streptozotocin induced diabetic rats, Journal of Ethnopharmacology, vol. 76, no. 3, pp. $269-277$.

Subroto, A. 2006. Ramuan Herbal untuk Diabetes Melitus. Jakarta: Penebar Swadaya

Van Steenis, C.G.G.J. 2005. Flora. Jakarta : PT. Pradnya Paramita. 